\title{
A comparison of artificial neural network model and logistics regression in prediction of companies' bankruptcy (A case study of Tehran stock exchange)
}

\author{
Ali Mansouri ${ }^{1}$, Arezoo Nazari ${ }^{2}$ and Morteza Ramazani ${ }^{3 *}$ \\ Department of Management and Accounting, University of Zanjan, Zanjan, Iran ${ }^{1}$ \\ Department of Accounting, College of Human Science, Saveh Branch, Islamic Azad University, Saveh, Iran ${ }^{2}$ \\ Young Researchers and Elite Club, Zanjan Branch, Islamic Azad University, Zanjan, Iran ${ }^{3}$
}

Received: 16-April-2016; Revised: 20-May-2016; Accepted: 23-May-2016

(C)2016 ACCENTS

\begin{abstract}
This paper aims to focus on the comparison of the artificial neural network model and logistic regression model in the prediction of companies' bankruptcy in Tehran stock exchange (TSE) in 3,2 and 1 year in advance. This study exercises an analytic-mathematical approach which has been utilized three-layer artificial neural network tools, which includes one hidden layer and one output neuron and logistic regression (LR) with seven independent variable and one dependent variable for testing research's hypotheses. Although the given results illustrates the high potential capacities of both models in the prediction of bankruptcies in an interval of three years, two years and one year before bankruptcy, capacity of neural network model showed the relative higher capability than LR model. This study takes into consideration the comparison of two popular tools of artificial neural networks (ANNs) and LR in bankruptcy prediction that are of importance in their own type.
\end{abstract}

\section{Keywords}

Logistic regression (LR), Artificial neural networks (ANNs), Tehran stock exchange (TSE), Bankruptcy prediction.

\section{Introduction}

Technology's high pace, broad environmental changes and their impacts on world's business has been resulted in increasingly fluctuations in economies in a way that restricts economical organization's competitive norms in gaining interest and increased the risk of bankruptcy as well. In such environment, any organization to maintain their competitive edge, the need for efficient decision in financial and non-financial field has been rising in importance. Since it's always accompanied by a risk due to future lack of certainty. As [1] notes: "Ignorance of concern critical situations of companies' lifetime and possible bankruptcy in the future will inflict exorbitant drawbacks on each companies' beneficiary. Required planning for stopping companies' bankruptcies can be done only by the prediction of their collapse; therefore, one of the ways to assist investors and managers is to present predictive patterns regarding companies' financial condition. The more predictions close to the reality, the more precise decision basis.

\footnotetext{
*Author for correspondence
}

Bankruptcy's prediction pattern is one of the tools which can estimate the future condition of companies."

Investors and creditors have the greatest willingness for prediction of organizations' bankruptcy. Since, once they face bankruptcy, they undergo great loss. Any patterns for prediction of bankruptcy have their own advantages and disadvantages New studies on ANN realm illustrate that ANN are great tools for detecting pattern classification using non-linear, nonparametric and synchronic learning. Also new researches have revealed that ANN model has been used for solving numerous financial issues, such as predicting bankruptcy and so on [2].

And finally ANN prediction models are known as one of the best techniques and models which predict the companies' future condition and estimate bankruptcy's contingency applying a combination of some financial ratios. However, in order to prove the strong capability of ANN models in the prediction of companies' future situation, this paper aims to focus on the prediction of the company's future condition with comparative approach, comparing ANN and LR, in order to judge about their capability in prediction, 
considering the interval of 3 years, 2 years, and 1 year before bankruptcy. However, the researcher intends to control, prediction capability of LR through statistical techniques and ANN prediction capability with ANN rule.

\section{Literature review}

\subsection{Bankruptcy}

In the first academic studies on bankruptcy, company's incapability was defined as increases in the probability of not being able to payback the main debt [3]. In other words, in the company's cash flow, bankruptcy is considered as a condition in which company's cash flow is less than the accumulation of expenses regarding long term debt [4]. From the economic point of view, bankruptcy can be interpreted as a company's potential perspective for drawback and losses, declared as company's bankruptcy. In fact, in this condition, the company's efficiency rate is less than the capital's expense rate [5]. Finally, [6] has classified bakruptcy's elements in two categories of internal and external factors. He suggests wrong decision making of managers as internal elements and commercial complexities as external factors of bankruptcy, which can impede organizational progress and its competitive capability. However, managers using their own and their subordinate creativity and innovativeness can cope commercial complexities too. Thus, applying any dependable prediction technique not only helps manager and investor to see the organization perspective in advance, but also it provides opportunities to prevent future frustration and failure. Classification of bankruptcy indicators from the other point of view will help us to see the organizational situation clearly and decide on issues more logical than before. Therefore, in this section other failure elements have been introduced. Credit management and expenses directing are two critical factors that take a great deal of considerations in the current paper.

\section{a) Credit management}

Optimal financing and usage of credit is referred as financial management in any organization. Efficient financial management directly affects the cost of product and by this means to reinforce the marketing process and customer satisfaction. But, there are some problems which are important as to be considered in credit management including:

- Ineffective credit management

- Low budget

- Betrayal and cheating
- It is obvious that the existence of any of these inefficiencies results in enterprises' to be encountered with complicated difficulty in their present and future organizational life.

\section{b) Expenses directing}

Presenting some materials due to bankruptcy's expenses seems to be important too, in the popular classification of bankruptcy's relative expenses, they are classified in four categories:

- Real expenses that are imposed owing to organizational inefficiencies.

- Real expenses that are imposed directly by debtors.

- Apprehended companies' properties that have been neutralized by other entity's interests.

- Real expenses that are imposed by competitors.

Knowing these elements and taking them under control will help companies to overcome future difficulty.

Additionally, bankruptcy's impact can be observed not only in the company itself, but also it can affect on society too. In fact, the cost of companies' bankruptcy is imposed on society as well as the companies themselves, and it can be said that the expenses of bankruptcy are quite high.

\subsection{Bankruptcy's prediction and their model}

The investors undeniably intend to reduce the risk of their major and minor capitals from being burned away by the prediction of the probability of a company's bankruptcy; therefore they attempt to find the methods to estimate the companies' potential bankruptcy. Because when they face with bankruptcy, the price of company stock will drop dramatically. Thus, the prediction of bankruptcy increasingly gains in importance. Therefore, stakeholders look for dependable techniques to predict the companies' future situation. This purpose is fulfilled by various methods among which the given methods, the method of analyzing ratios and the method of analyzing the market risk are of highest importance. In the method of analyzing the market risk, the bankruptcy Symptoms will occur through differences in market risk (e.g. variance of efficiency rate and systematic risk) thus it will be able to be estimated. For these purposes, in analyzing the ratios, bankruptcy Symptoms are estimated by a group of financial ratios combined together by experts. 
As mentioned above, identifying basic ratios is the vital process in this kind of studies. After that, recognizing a powerful technique which can utilize these ratios to anticipate companies' future highly gains in importance. In order to accomplish verified, objective, three main models in the present paper have been introduced: statistical models, artificial intelligence models, and theoretical models. Each of these models is described separately below:

2.2.1 Statistical models

In these models, the standard classical modeling is used, and concentrates on business failure. The required variables in creating these models are generally played dominant role in the prediction process. However, statistical models can be classified in two groups:

Descriptive statistical techniques which focus on the analysis of a dominant financial ratios, and their logic is based on the principle that if bankrupted companies' financial ratios significantly differs from non-bankrupted companies' financial ratios it can be concluded that the company tends to be bankrupt, these ratios can be referred to as bankruptcy's predictive variables such as [5] model.

The second model of bankruptcy prediction can be referred to as inferential statistical models which increasingly appeals by many researchers to predict companies future situation. Thus, a lot of researches based their works on this kind of analyses. These models are classified into many categories. The most applicable models are as follows:

1- Artificial Intelligence Techniques

2- Neural Networks

3- Logit Models

2.2.2Artificial intelligence techniques

Artificial intelligence models apply patterns such as human kind knowledge, intelligence, and the logic. Artificial intelligence techniques are, in fact, the ones which learn and develop their problem solving operations according to previous experiences. These techniques are highly depending on computer technology. In the field of bankruptcy, these models focus on the commercial incapability signals, these signals can be referred as key predictor variables. They are extracted from companies' financial statements. Intelligent techniques are compounded of artificial neural networks, genetic algorithm and fuzzy logic.

2.2.3Neural networks

Neural Networks is one of the well-known non-linear techniques that can be used in many prediction algorithms such as prediction of the output, the stock price, stock's efficiency, bankruptcy prediction, categorizing stock exchange and etc.

83
This algorithm follows the human being brain structure in learning from experience and designing a model to predict future events. The human brain contains numerous neurons. These neurons are connected to each other by some fibers which called 'Axon, and all of their forms networks that called 'biological neural network', every artificial neural network is a computerized system that works such as a biological neural network from many dimensions. To sum it up, an artificial neural network is a bundle of artificial neurons that are in connection with each other via some connection that called 'communications'. The ideal purpose of an artificial neural network is to achieve biologic neural network capabilities in detecting patterns, categorizing, restoring and solving complicated problems.

Among many artificial neural networks, the most common artificial neural networks are Multilayer Perception (MLP) that are regulated hierarchically and connected to each other. Any input layer (through which external information is received) is related to single or multiple hidden-layers, and the hidden-layers are also connected to output layers. Where the model designed to create an algorithm to predict bankruptcy, some ratios are considered as input variables, and the condition of the companies (bankrupted, and non-bankrupted) is considered as network output. Hidden layer in the pattern creates logical relations between input and output variables so that by using designed pattern, it will be possible to predict any other company's situation - called test group - which is unknown yet.

In other words, artificial neural network by learning the relationship between output and input variables, designs, theoretical model which able to predict unknown outputs through applying certain inputs and designed network. Their many works, conducted to predict companies bankruptcy by neural networks. Among them we can refer to [7] [8] [9] and [10] as pioneers of ANN user for bankruptcy production and then applied ANN tools with different and progressive procedure in his research for predicting bankruptcy [11].

2.2.4Logistic regression (LR)

Logistic Regression technique (LR) is a multivariable analysis that concentrates on all the available predictive factors in a problem at the same time. In the LR, a concept with the name of odd ratio is used (probability of occurrence $p_{i}$ to probability of nonoccurence $1-p_{i}$ ) and this ratio's logarithm is calculated based on the following relation, this model is known as Logit model too [12]. 
$\ln \left(\frac{p_{i}}{1-p_{i}}\right)=\beta_{0}+\beta_{i} x_{i}$

This model can be used for predicting bankruptcy, and for the first time was used by for predicting banks' bankruptcy, and following him [13] applied logic model for predicting companies' commercial incapability and bankruptcy.

\section{Research's literature}

LR has been used for predicting companies' bankruptcy [14]. In [15] a model was presented using capital's variables to all properties, tax to all properties, profit prior to tax to current debt and total sale of all properties, which its precision was 93.5\%. In [13] authors was first applied a comprehensive model of LR for predicting bankruptcy, considering that his model included 2058 safe companies, and 105 bankrupted companies, and it can be said that his study has been the most comprehensive study since that time, and he extracted predictive model which was able to predict the companies' bankruptcy for one, second and third year before bankruptcy up to $85.10 \%, 87.6 \%$, and $82.6 \%$ respectively. He used total debt's ratio variable for total property, and pure interest's ratios to sum of properties and introduced them as the best discriminatory ratios in his model. Fulmer et al. [19] analyzed 20 financial ratios, and selected 9 key ratios, and through this process he designed his model. His research ascertained that the designed model was able to obtain $98 \%$ success in the prediction of bankruptcy a year in advance. While this model's success in the prediction of bankruptcy was $88 \%$ for two years before the bankruptcy. In [13] a model was presented, which was able to predict with the sufficiency of $81 \%$ and $84 \%$ using ANN in a year and two before bankruptcy, respectively. ANN has better performance in comparison with logic analysis in predicting companies' bankruptcy [7] [16] [17]. Over other models, ANNs are better in predicting companies' bankruptcy [18]. All the researchers emphasize high efficiency of ANN in bankruptcy prediction.

Research Hypotheses:This paper uses the hypotheses below to achieve the purpose of research: Main hypothesis:

\section{Companies' bankruptcy can be predicted by using ANN and LR model.}

Minor Hypotheses:

1. There is a possibility of companies' bankruptcy prediction three years in advance by the use of ANN and LR.
2. There is a possibility of companies' bankruptcy prediction two years in advance by the use of ANN and LR.

3. There is a possibility of companies' bankruptcy prediction three years in advance by the use of ANN and LR.

\section{Research methodology}

The method of study in this research is analyticmathematical. This study applies ANN and LR tools. Following a description of the concept of bankruptcy in this research, the required key variables in this study were introduced. Following that, pointing out the method of organizing the information of research model, neural network's optimized model introduced. Four layers perceptions network recognized as well suitable predictor for bankruptcy of companies. Then bankrupted and non-bankrupted in the years 2013 identified and companies' condition interned into the model to constitute model foundation.

We used to train data to design neural network model and then test data were applied to evaluate model efficiency. Prediction process was conducted using 2010 to 2012 companies' indicator variables and training data to predict bankruptcy of companies from 1 to 3 years in advance.

The LR model followed the same way to be designed. In this process, we remove the test data, such as a neural network model for designing process and then we used training data to develop LR model using 2010 to 2012 companies' indicator variables and training data to predict bankruptcy of companies from 1 to 3 years in advance. Then we used test data to evaluate the ability of the model to predict bankruptcy of companies.

4.1 Population, sampling method, and sample size Research's population is compounded of all of the accepted companies in TSE in an interval of 2010 to 2013. The research's sample is a number of companies that are classified into two groups of bankrupted and non-bankrupted companies.

The longitudinal sampling approach was used to select our sample. By this means, Morgan algorithm applied to select among bankrupted and nonbankrupted companies. As shown in Figure 1, the numbers of bankrupted companies were ascending from 2010 to 2013. 


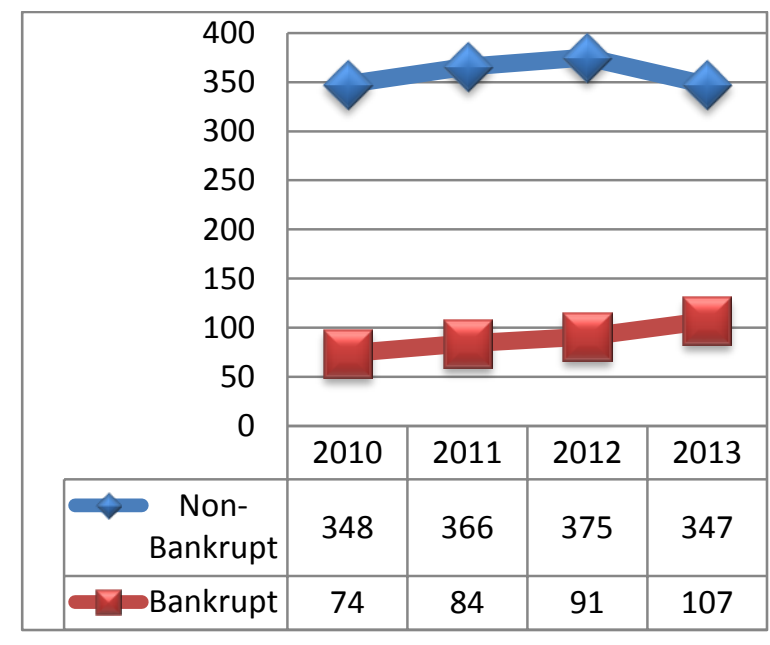

Figure 1 The chart and the table of bankrupted and non-bankrupted companies during the analysed years

4.2 The methods and data analysis tools

To reinforce model's ability, advanced statistical techniques are used which the most important of them are explained briefly above and for the sake of designing and applying the model, SPSS-MATLABSTATISTICA software is used.

\subsection{Research's variables and their calculation method}

The independent variable of this research is specified by this symbol $\left(\mathrm{x}_{\mathrm{i}}\right)$ which is depicted in Table 1 .

Table 1 Independent variables and their symbols

\begin{tabular}{|c|c|}
\hline Independent Variable & Symbol \\
\hline Net Cash Flow (NCF) & $\mathrm{X} 1$ \\
\hline Total Assists (TA) & $\mathrm{X} 2$ \\
\hline Total Debt (TD) & $\mathrm{X} 3$ \\
\hline Current Liability & $\mathrm{X} 4$ \\
\hline $\begin{array}{r}\text { cash flow to total } \\
\text { assets }(\mathrm{CF} / \mathrm{TA}))\end{array}$ & X5 \\
\hline $\begin{array}{r}\text { cash flow to total current } \\
\text { debts (CF/TCD) }\end{array}$ & X6 \\
\hline $\begin{array}{r}\text { cash flow to total debts } \\
\text { (CF/TD) }\end{array}$ & $X 7$ \\
\hline
\end{tabular}

Independent variables in present research are depicted introduced as dichotomous variable which shows a bankruptcy situation of companies. Table 2 . Demonstrate dependent variable from this point of view.

Table 2 Variables and its values

\begin{tabular}{lc}
\hline Bankrupt & 0 \\
\hline Non-Bankrupt & 1 \\
\hline
\end{tabular}

Scientific evaluation is crucial for the sake of hypothesis evaluation and providing time and opportunity for decision making for investors. Therefore, the more time for decision making available for the investor, the more precise decision will be made. Thus, if there exist models to help us in the long term, to predict companies' bankruptcy, they will be efficient in practice. For this purpose, though there are also different models for prediction that some of these models are ANN and LR. To gain from these two precise models, it is necessary to classify data into suitable categories. For this purpose, the data in 3 categories were classified which are depicted in Table 3.

Table 3 Information group show

\begin{tabular}{rrrr}
\hline Categories & Data \\
\hline Group 1 & 3 years before $\begin{array}{r}\text { bankruptcy } \\
\text { prediction }\end{array}$ \\
Group 2 & 2 years before $\begin{array}{r}\text { bankruptcy } \\
\text { prediction }\end{array}$ \\
Group 3 & 1 years before $\begin{array}{r}\text { bankruptcy } \\
\text { prediction }\end{array}$ \\
\hline
\end{tabular}

\section{Testing hypothesis}

To compare the neural network and logistic regression efficiency in the same condition, it will be useful to do this using hypothesis testing. For this purpose three hypotheses were developed, depicted below.

5.1 First hypothesis test: prediction of 3 years before bankruptcy,

5.1.1 LR model results

In order to predict companies' bankruptcy, the independent variable is used 3 years proceeding to bankruptcy and companies' situation (bankrupt or non-bankrupt) in the last year to design the LR model. SPSS software was applied to analyze data and extract coefficients. The given results from the LR evaluation are depicted in Table 4.

Table 4 In dependent variable coefficient in bankruptcy prediction and significance level for first group data using LR

\begin{tabular}{ccccc}
\hline $\begin{array}{c}\text { Independent } \\
\text { Variable }\end{array}$ & B & S.E. & Df & Sig. \\
\hline $\mathrm{X}_{1}$ & 0.001 & .000 & 1 & .369 \\
$\mathrm{X}_{2}$ & 0.021 & .000 & 1 & .020 \\
$\mathrm{X}_{3}$ & 0.005 & .000 & 1 & .465 \\
$\mathrm{X}_{4}$ & 0.041 & .000 & 1 & .018 \\
$\mathrm{X}_{5}$ & -27.480 & 16.080 & 1 & .087 \\
$\mathrm{X}_{6}$ & 11.705 & 12.458 & 1 & .347 \\
$\mathrm{X}_{7}$ & 12.414 & 18.923 & 1 & .512 \\
Constant & -.117 & .538 & 1 & .828 \\
\hline
\end{tabular}


As depicted in the above table, among independent variables, the sum of total properties $\left(\mathrm{x}_{2)}\right.$, the sum of total current debt $\left(\mathrm{x}_{4}\right)$, and the ratio of cash flow to total properties $\left(\mathrm{x}_{5}\right)$ has a meaningful effect on bankruptcy. Thus, it can be concluded that LR model, designed for companies' bankruptcy prediction is a meaningful model and the LR model has the capability of bankruptcy predicting. Estimator model is described as follows:

$\mathrm{P}(\mathrm{x})=$

$\mathrm{e}^{\beta 1 \mathrm{x}(1-1)+\beta 2 \mathrm{x}(1-2)+\beta 3 \mathrm{x}(1-3)+\beta 4 \mathrm{x}(1-4)+\beta 5 \mathrm{x}(1-5)+\beta 6 \mathrm{x}(1-6)+\beta 7 \mathrm{x}(1-7)}$ $1+\mathrm{e}^{\beta 1 \mathrm{x}(1-1)+\beta 2 \mathrm{x}(1-2)+\beta 3 \mathrm{x}(1-3)+\beta 4 \mathrm{x}(1-4)+\beta 5 \mathrm{x}(1-5)+\beta 6 \mathrm{x}(1-6)+\beta 7 \mathrm{x}(1-7)}$

$\mathrm{p}(\mathrm{x})=$

$\mathrm{e}^{0.01 \mathrm{x} 1+0.0021 \times 2+0.005 \times 3+0.041 \times 4-27.480 \times 5+11.705 \times 6+12.414 \times 7}$

$1+\mathrm{e}^{0.01 \mathrm{X} 1+0.0021 \mathrm{x} 2+0.005 \times 3+0.041 \times 4-27.480 \times 5+11.705 \times 6+12.414 \mathrm{X} 7}$

By using the model for selected training data in the first group, the following results are attained.
Table 5 Comparing model prediction and real companies' situation

\begin{tabular}{cccc}
\hline Companies & \multicolumn{2}{c}{ Model Prediction } & Prediction \\
\cline { 2 - 3 } Situation & Bankrupt & $\begin{array}{c}\text { Non- } \\
\text { Bankrupt }\end{array}$ & Percent \\
Bankrupt & 7 & 12 & 36.8 \\
Non- & 4 & 95 & 96.0 \\
Bankrupt & & & \\
Overall & & & 86.4 \\
Bankrupt & & & 36.8 \\
\hline
\end{tabular}

As depicted in Table 5, LR model predicts bankrupted companies 3 years in advance with $36.8 \%$ efficiency, and predicts non-bankrupted companies with $96 \%$ efficiency, and it has $86.4 \%$ predictability in total; therefore, we can conclude that LR can predict bankrupted companies in the first group with the rather good capability.

5.1.2 ANN model results

As it is depicted in this stage of research, ANN has four hidden-neurons, and two bankrupted and nonbankrupted outputs.

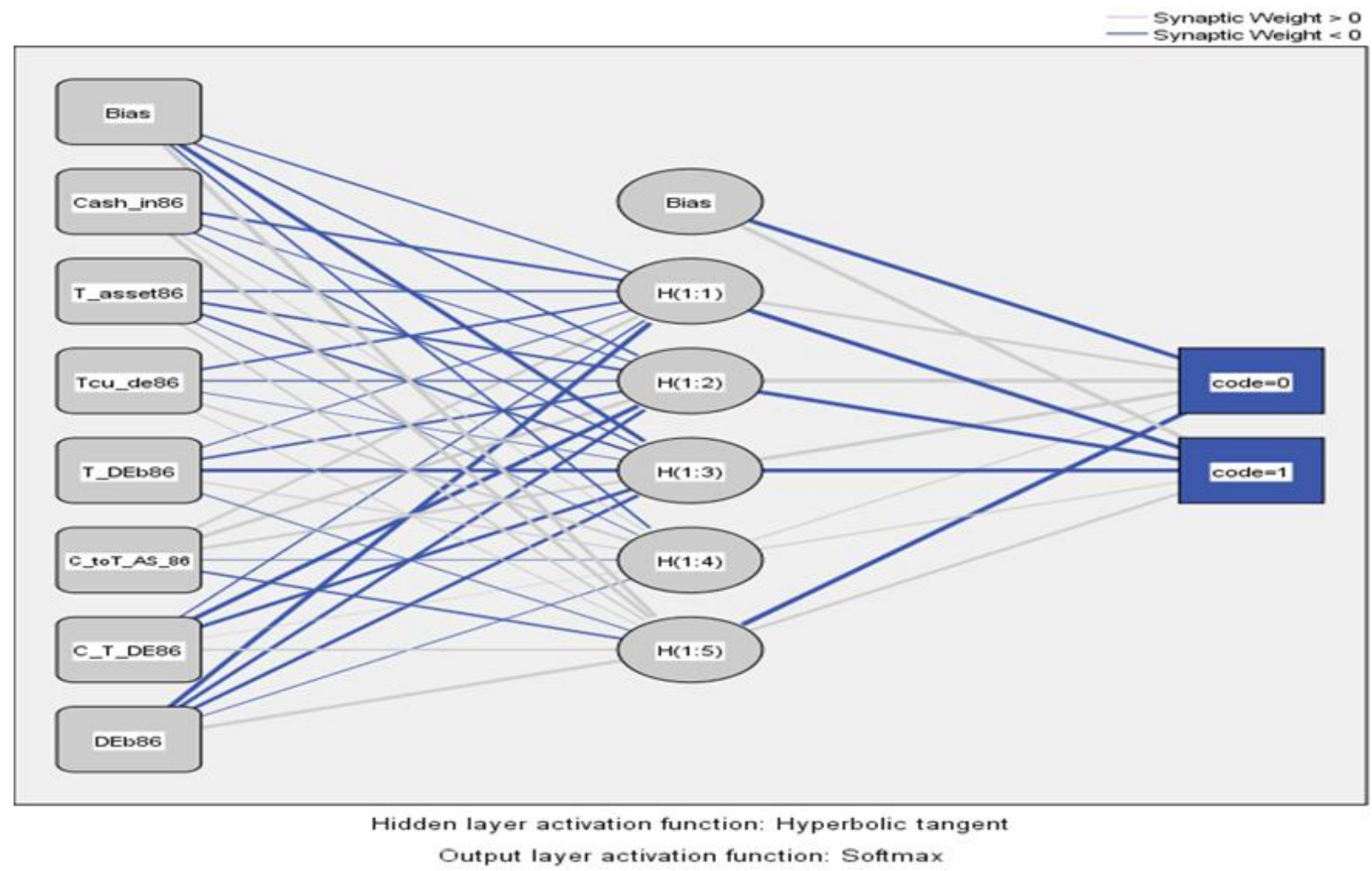

Figure 2 Artificial ANN model for the first group

In order to predict companies' bankruptcy, three years prior to bankruptcy using the ANN model, independent variable and companies' situation are entered into the model, and STATISTICA software has been used, ANN prediction results are depicted in Table 6. Figure 2 shows the ANN model for the first group. 
Table 6 The artificial ANN model for first group

\begin{tabular}{lcccc}
\hline & $\begin{array}{c}\text { Real Situation } \\
\text { Model Result }\end{array}$ & Bankrupt & Non-Bankrupt & Prediction Percent \\
\hline Training & Bankrupt & 8 & 2 & 0.72 \\
& Non-Bankrupt & 4 & 61 & 0.93 \\
Overall & & & 0.92 \\
Test & Bankrupt & 6 & 34 & 0.75 \\
& Non-Bankrupt & 1 & & 0.95 \\
\hline
\end{tabular}

In the test group, the model capability to predict companies' bankruptcy is $75 \%$ and to predict nonbankrupt for the next three years has become $95 \%$. Thus we can conclude that ANN with total 93\% efficiency will have a more authentic prediction for three years before the bankruptcy. Therefore, as pointed out above, LR with $86.4 \%$ has less efficiency than ANN by $93 \%$, thus ANN has the most precise capability in three in advance for bankruptcy prediction. This difference is depicted in Figure 3.

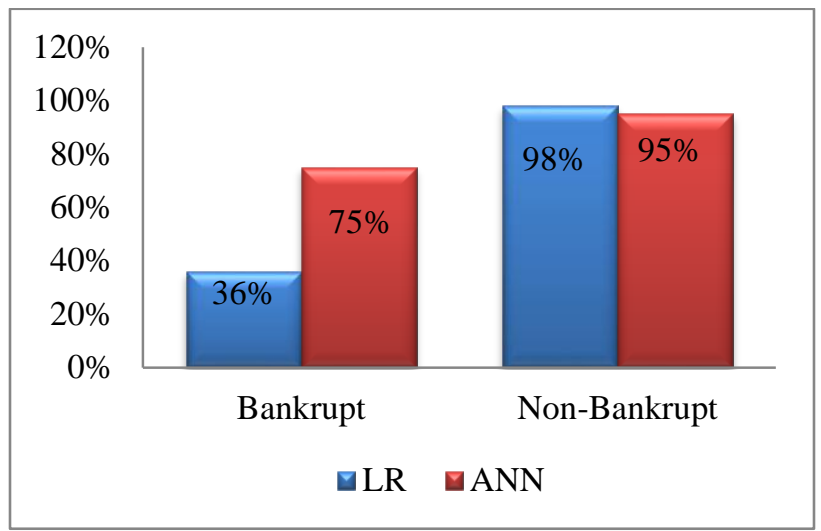

Figure 3 Two models' efficiency comparison, total for the first group

Here, we have drawn a chart for the comparison of the efficiency of the above models for the first group's data so that suitably distinguish model's efficiency (Figure 4).

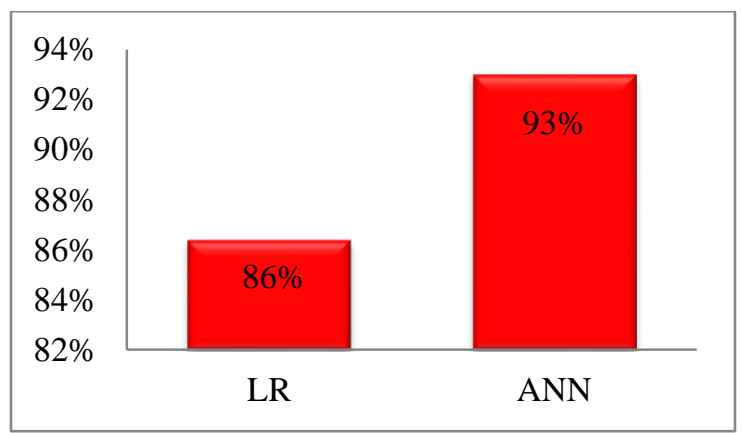

Figure 4 Two models total efficiency comparison for the first group

87
According to figure 4 which depicts two model's capability (both about bankrupted and nonbankrupted companies), it can be seen that both models have great capabilities for prediction, and have less difference in prediction.

\subsection{Second hypothesis test: predicted 2 years} before the bankruptcy

\subsubsection{LR model's result}

Since predicting companies' bankruptcy two years before the bankruptcy, independent variable and model coefficient basically is defined using the LR model.

Table 7 Investigating descriptive levels of second hypothesis using the LR model

\begin{tabular}{rrrrr}
$\begin{array}{c}\text { Independent } \\
\text { Variable }\end{array}$ & B & S.E. & D.F & Sig. \\
\hline X1 & 0.004 & .000 & 1 & .264 \\
X2 & 0.006 & .000 & 1 & .010 \\
X3 & 0.001 & .000 & 1 & .120 \\
X4 & 0.0081 & .000 & 1 & .008 \\
X5 & -23.502 & 16.249 & 1 & .148 \\
X6 & -0.119 & .264 & 1 & .651 \\
X7 & 15.641 & 10.644 & 1 & .142 \\
Constant & -.251 & .472 & 1 & .595 \\
\hline
\end{tabular}

As depicted in Table 7 from among independent variables sum of total properties $\left(\mathrm{x}_{2}\right)$ and the sum of total current debt $\left(\mathrm{x}_{4}\right)$ has meaningful impact on predicting bankruptcy; therefore, it can be concluded that the LR model has the capability of bankruptcy prediction.

Regression model's estimator is denoted as below:

$\mathrm{P}(\mathrm{x})=$

$\frac{\mathrm{e}^{\beta 1 \mathrm{x}(2-1)+\beta 2 \mathrm{x}(2-2)+\beta 3 \mathrm{x}(2-3)+\beta 4 \times(2-4)+\beta 5 \times(2-5)+\beta 6 \times(2-6)+\beta 7 \times(2-7)}}{1+\mathrm{e}^{\beta 1 \mathrm{x}(2-1)+\beta 2 \times(2-2)+\beta 3 \times(2-3)+\beta 4 \times(2-4)+\beta 5 \times(2-5)+\beta 6 x(2-6)+\beta 7 x(2-7)}}$

$\mathrm{p}(\mathrm{x})=$

$\mathrm{e}^{.002 \times 1+.006 \times 2+.001 \times 3+.008 \times 4-23.502 \times 5-0.119 \times 6+15.614 \times 7}$

$1+\mathrm{e}^{.002 \times 1+.006 \times 2+.001 \times 3+.008 \times 4-23.502 \times 5-0.119 \times 6+15.614 \times 7}$

The selected training data and above model were used and analyzed for the second group, the given results are demonstrated in Table 8. 
Table 8 Analyzing LR model efficiency using second group data

\begin{tabular}{cccc}
$\begin{array}{c}\text { Companies } \\
\text { Situation }\end{array}$ & \multicolumn{2}{c}{ Model Result } & Prediction \\
\cline { 2 - 3 } Percent & Bankrupt & $\begin{array}{c}\text { Non- } \\
\text { Bankrupt }\end{array}$ & \\
Bankrupt & 8 & 11 & 42.1 \\
$\begin{array}{c}\text { Non- } \\
\text { Bankrupt }\end{array}$ & 5 & 94 & 94.9 \\
Overall & & & 86.4 \\
\hline
\end{tabular}

As seen in the above table, LR model can predict the bankruptcy two years in advance with the capability of $42.1 \%$, and capability for predicting nonbankruptcy is equal to $96.9 \%$, this proportion for whole prediction is $86.6 \%$. Thus we can say that the LR model with about $86 \%$ of capability is able to predict bankruptcy 2 years in advance.

5.2.2 ANN model results

As can be seen in this stage of research, ANN has 4 hidden-neurons and two outputs of bankruptcy and non-bankruptcy.

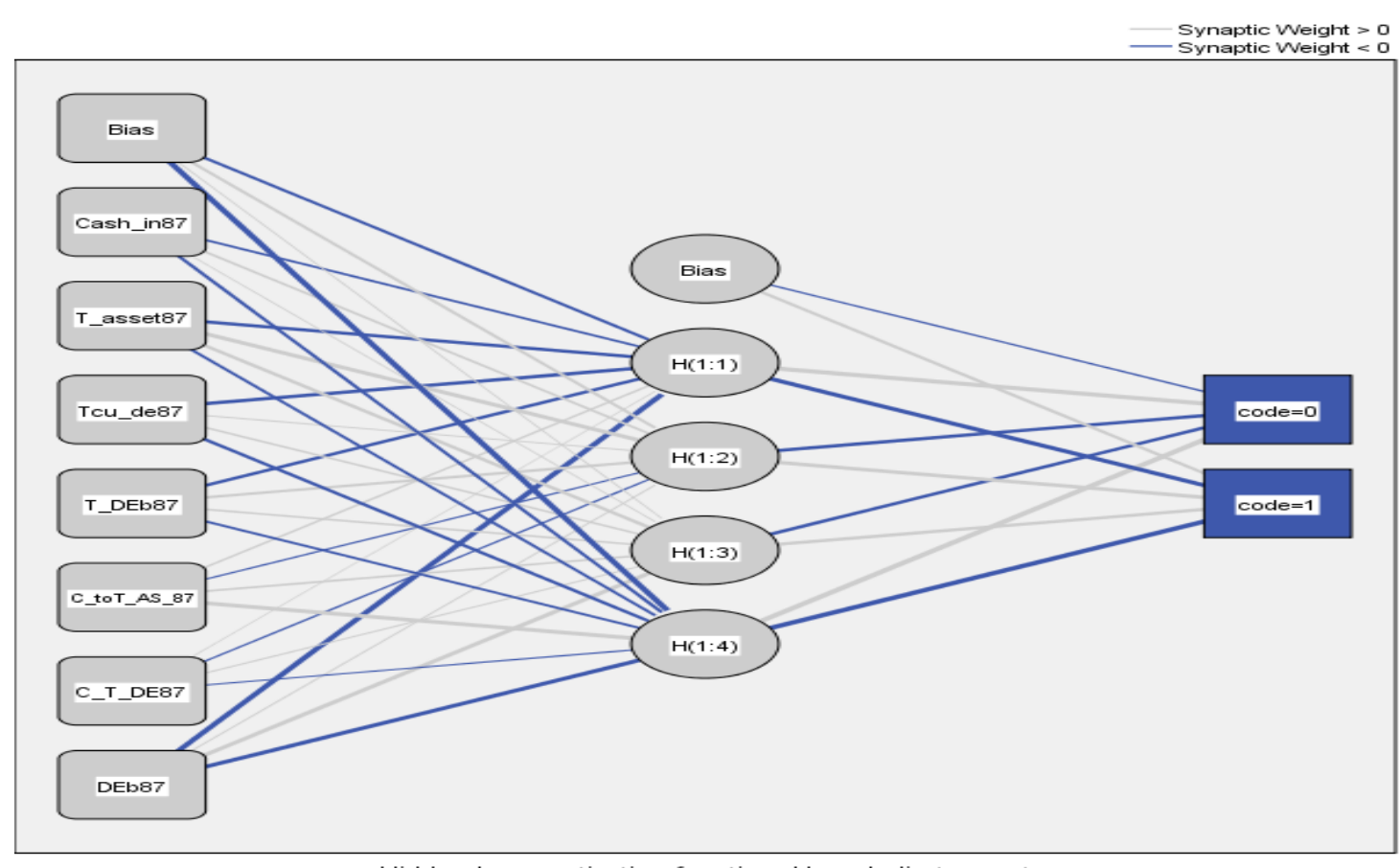

Hidden layer activation function: Hyperbolic tangent Output layer activation function: Softmax

Figure 5 Multi-layer perceptions ANN for the second group's data with 7 inputs, and 4 hidden-neurons, and 2 outputs

In order to predict companies' bankruptcy two years in advance, the independent and considered variable was specified according to the definition using ANN
Model and STATISTICA software was used as well, the results of ANN analysis is depicted in Table 9. Figure 5 shows the Multi-layer perceptions ANN for the second group.

Table 9 ANN model's Efficiency Analysis using second group's data

\begin{tabular}{ccccc}
\hline & & Bankrupt & Non-Bankrupt & Prediction Percent \\
\hline \multirow{3}{*}{ Training } & Bankrupt & 11 & 2 & 0.84 \\
& Non-Bankrupt & 0 & 71 & 100 \\
Overall & & & 0.97 \\
Test & Bankrupt & 6 & 1 & 0.85 \\
& Non-Bankrupt & 1 & 27 & 0.96 \\
& Overall & & & 0.94 \\
\hline
\end{tabular}


According to Table 9 ANN model's for the second group is as follows:

For predicting company's bankruptcy in the training group, ANN model has $84 \%$ of capability. However, for predicting company's non-bankruptcy, it has prediction capability equal to $100 \%$. And in the test group, prediction of the company's bankruptcy before the next two years was $85 \%$ and the prediction of non-bankruptcy of companies was $96 \%$.

5.2.3 The comparison of ANN and LR model for the second group

As it can be seen in the above analysis, LR model with $84.6 \%$ has less capability than ANN by $94 \%$, and ANN has totally the most capable in prediction two years prior to bankruptcy. This difference is depicted in Figure 6.

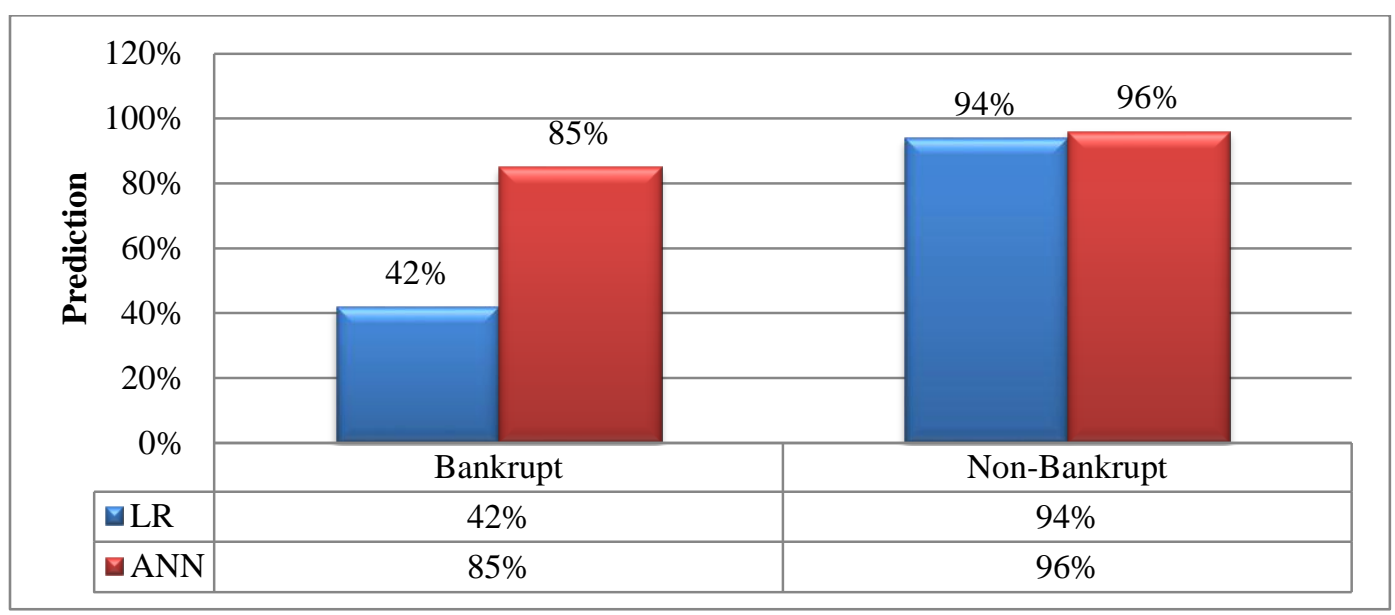

Figure 6 Two models' comparison chart for predictive capability for the second group

As it can be seen, ANN's capability for prediction of companies' bankruptcy for the next two years is more than LR, and also, ANN's capability for prediction of non-bankruptcy for the next two years is more than LR, though their difference is not so much. It has been shown here in Figure 7 to compare of the above models result for the second group

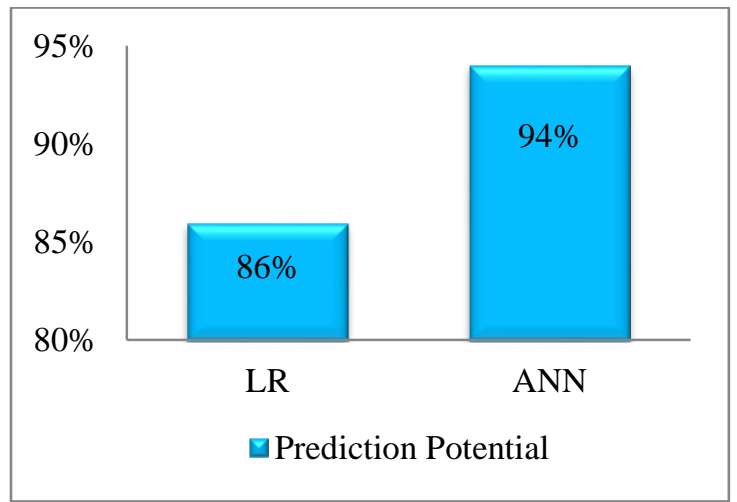

Figure 7 Both models' total efficiency comparison of group (2)

According to Figure 7 both models' capability for prediction (bankruptcy and non-bankruptcy) is power in other words, Both models have high capability for predicting.
5.3 Third hypothesis test: The bankruptcy prediction one year in advance

5.3.1 LR model's results

Table 10 Meaningful level analysis of the third group's data using the LR model

\begin{tabular}{ccccc}
$\begin{array}{c}\text { Independent } \\
\text { Variable }\end{array}$ & B & S.E. & DF & SIG. \\
\hline X1 & 0.09 & .000 & 1 & .715 \\
X2 & 0.04 & .000 & 1 & .008 \\
X3 & 0.03 & .000 & 1 & .080 \\
X4 & 0.05 & .000 & 1 & .010 \\
X5 & -2.201 & 4.163 & 1 & .597 \\
Constant & -.263 & .554 & 1 & .635 \\
\hline
\end{tabular}

As seen in the Table 10, the sums of total properties (x2), and total sum of current assets (x4), have the meaningful effect in predicting bankruptcy, so it can be concluded:

In LR model, the model selected for predicting companies is the meaningful one; in other words, companies' bankruptcy can be predicted using the LR model. Regression model of the estimator is as follows:

$P(x)=\frac{e^{\beta 1 x(3-1)+\beta 2 x(3-2)+\beta 3 x(3-3)+\beta 4 x(3-4)+\beta 5 x(3-5)}}{1+e^{\beta 1 x(3-1)+\beta 2 x(3-2)+\beta 3 x(3-3)+\beta 4 x(3-4)+\beta 5 x(3-5)}}$ 
Arezoo Nazari et al.

$P(x)=\frac{\mathrm{e}^{0.09 \times 1+0.04 \times 2+0.03 \times 3+0.051 \times 4-2.201 . \times 5}}{1+\mathrm{e}^{0.09 \times 1+0.04 \times 2+0.03 \times 3+0.051 \times 4-2.201 . \times 5}}$

Using the above models, the training data are analyzed in the third group, and the given results are depicted in Table 11.

Table 11 LR model's efficiency using third group data

\begin{tabular}{lccc}
\hline Real & \multicolumn{2}{c}{ Model Result } & Prediction \\
Situation & Bankrupt & $\begin{array}{l}\text { Non- } \\
\text { Bankrupt }\end{array}$ & Percent \\
Bankrupt & 9 & 10 & $47 \%$ \\
$\quad$ Non- & 4 & 95 & $96 \%$ \\
Bankrupt & & & \\
Overall & & & $88 \%$ \\
\hline
\end{tabular}

As can be seen in Table 11, LR model's prediction capability is $47 \%$ from a year before the bankruptcy for bankrupted companies, and this model's capability for non-bankruptcy companies is $96 \%$, this result demonstrate considerable capability for prediction one before issues come up. In other words, this model's capability is high. LR model has totally $88 \%$ capability for predicting the third group, the prediction capability of this group is higher than the first two groups; therefore, it can be concluded that the loss interval between predicting years and the event year reinforce the power of predictability for LR model.

5.3.2 ANN model's results

As seen at this stage of research, ANN has 4 hiddenneurons again, and has two bankruptcy and nonbankruptcy outputs neurons.

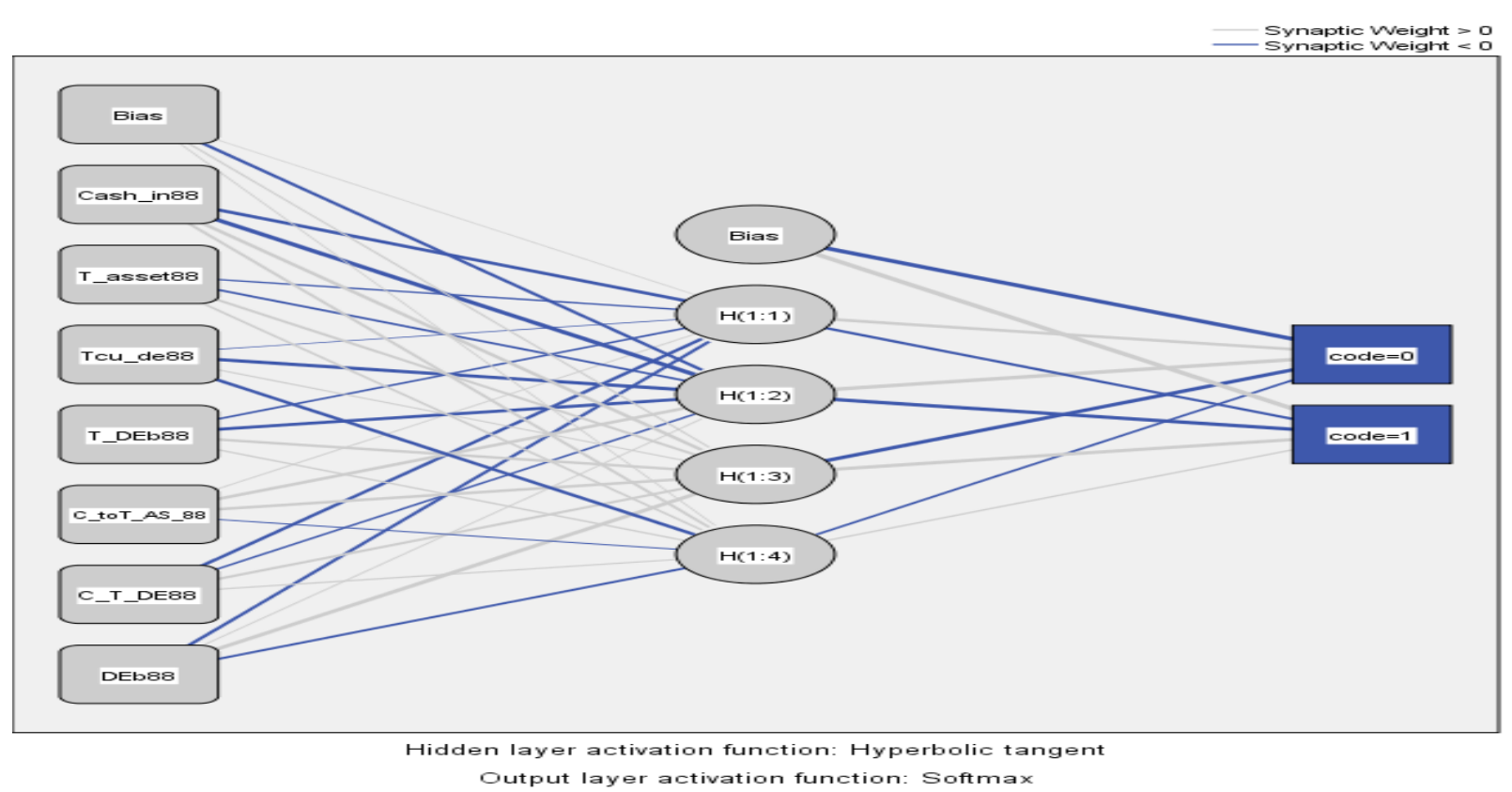

Figure 8 ANN model for the third group

Table 12 Investigating ANN model efficiency using third group data

\begin{tabular}{ccccc}
\hline Training & Bankrupt & $\begin{array}{c}\text { Non- } \\
\text { Bankrupt }\end{array}$ & $\begin{array}{c}\text { Predicti } \\
\text { on } \\
\text { Percent }\end{array}$ \\
\hline \multirow{4}{*}{ Test } & Bankrupt & 12 & 2 & $85 \%$ \\
& $\begin{array}{c}\text { Non- } \\
\text { Bankrupt }\end{array}$ & 0 & 70 & $100 \%$ \\
& Overall & & & \\
& Bankrupt & 7 & 1 & $97 \%$ \\
& Non- & 1 & 28 & $96 \%$ \\
& Bankrupt & & & \\
& Overall & & & $94.5 \%$ \\
\hline
\end{tabular}

For predicting companies' bankruptcy one year in advance, independent variables basically are defined using an ANN model, and STATISTICA software is used. Figure 8 shows the ANN model for third group.

For training group, ANN model's capability for predicting bankruptcy a year before bankruptcy is $84 \%$, and also, the capability of the model for predicting company's non-bankruptcy is $100 \%$. (Table12).

In training data groups, ANN model's capability in predicting bankruptcy, a year before bankruptcy's due to training date is $87.5 \%$ in predicting company's 
bankruptcy, and the capability of the company's nonbankruptcy prediction of ANN model is $0.96 \%$. And, totally, this model's capability for prediction is $94.5 \%$. So it can be concluded that, the loss interval between the prediction year and the given year reinforce ANN's predictability.

5.3.3 ANN and LR model's efficiency comparison of the third group

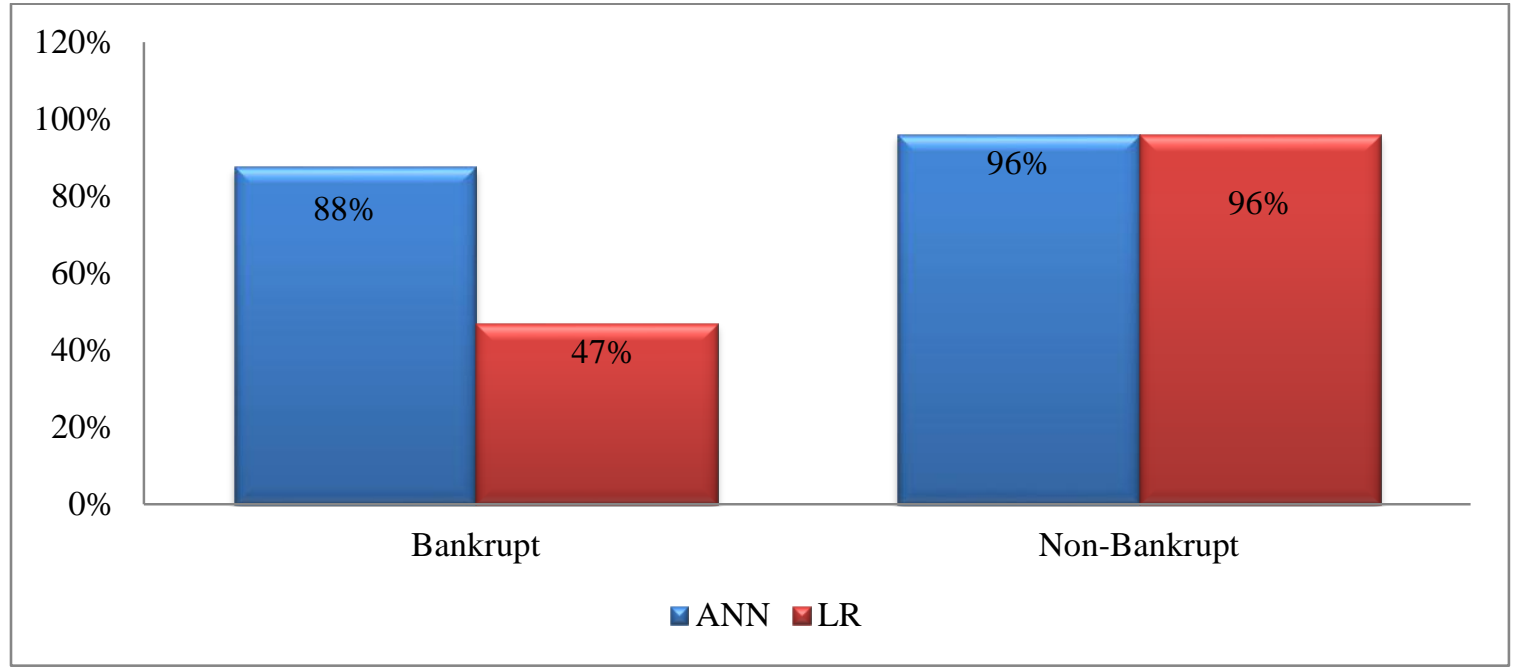

Figure 9 Two models' predictability for the third group

According to the above tables and charts, both ANN and LR have the capability of predicting bankruptcy one year before bankruptcy. The essential matter in this research is that both models have high capability for predicting the companies' future situation. So, the third minor hypothesis will be confirmed. Model predictability for the third group is shown in Figure 9. Efficiency comparison of the both models is shown in Figure 10.

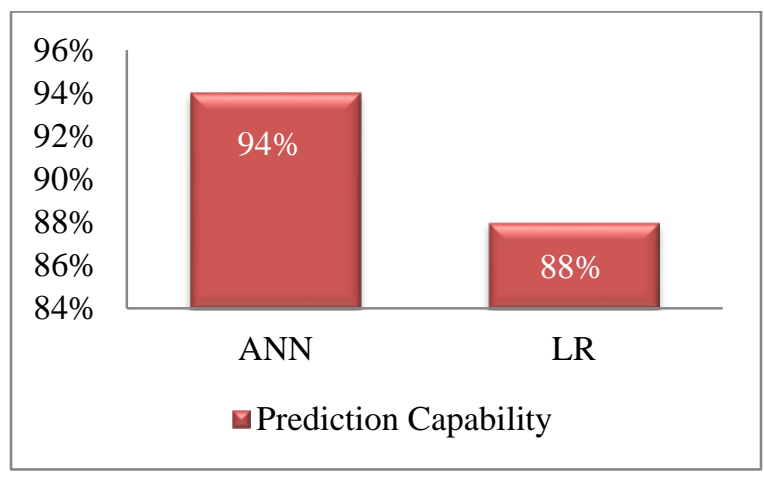

Figure 10 Efficiency comparison of the both models of the total for the third group's data

\subsection{ANN and LR model comparison in predicting} bankruptcy using first, second and third group Now at the end of this section we intend to analyze and compare ANN and LR prediction results in each three categories to choose the most precision models for any group. In Figure 11 whole comparison of ANN and LR model can be seen.

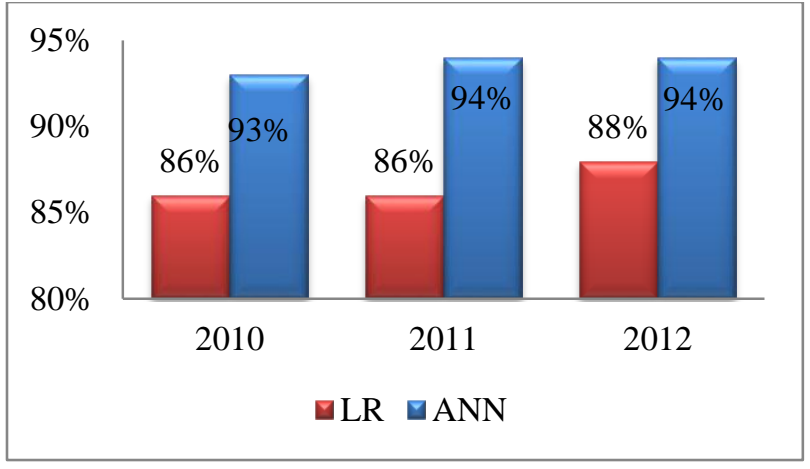

Figure 11 ANN and LR model comparison in predicting bankruptcy for all groups

As depicted in Figure 11, ANN model has high efficiency in predicting in all three groups, particularly in the third group (a year before the event), and its correspondent LR model has the relative high capability for bankruptcy prediction for one year in advance as well.

\section{Conclusion}

The present research results show that the ANN has better performance than LR in different intervals. In the three years before the bankruptcy, ANN with 93\% efficiency has more capability than LR by $86.4 \%$, while in [19] with $88 \%$ efficiency and in [15] study with $84 \%$ efficiency were for two years before 
bankruptcy using the ANN model. Thus we can suggest that research's variables (financial ratios) were used in this research are important for predicting two years before the bankruptcy. ANN has $94 \%$ efficiency for one year before bankruptcy in comparison with LR's $84 \%$ efficiency too. Fulmer et al. [19] studies also for one year before bankruptcy were $98 \%$ and $81 \%$ respectively. According to research's background, the most important strength of this study was predicted of bankruptcy three years in advance that can help managers to stop benefactor's loss by preventing bankruptcy and finally providing an extra year for a reaction, it will help manger to handle in efficiencies and prevent bankruptcy accordance.

\section{Acknowledgment}

None.

\section{Conflicts of Interest}

The authors have no conflicts of interest to declare.

\section{References}

[1] Saghafi A. Evaluation of bankruptcy predicting factors in Iranian environmental. $\mathrm{PhD}$ thesis, Tehran University. 2002.

[2] Lee KC, Han I, Kwon Y. Hybrid neural network models for bankruptcy predictions. Decision Support Systems. 1996; 18(1):63-72.

[3] Gordon MJ. Towards a theory of financial distress. The Journal of Finance. 1971; 26(2):347-56.

[4] Whitaker RB. The early stages of financial distress. Journal of Economics and Finance. 1999; 23(2):12332.

[5] Weston JF, Brigham EF. Essentials of managerial finance. Dryden Press; 1990.

[6] Shah JR, Murtaza MB. A neural network based clustering procedure for bankruptcy prediction. American Business Review. 2000;18(2):80-6.

[7] Newton GW. Bankruptcy and insolvency accounting, practice and procedure. John Wiley \& Sons; 2009.

[8] Odom MD, Sharda R. A neural network model for bankruptcy prediction. In international joint conference on neural networks 1990 (pp. 163-8).

[9] Zhang G, Hu MY, Patuwo BE, Indro DC. Artificial neural networks in bankruptcy prediction: General framework and cross-validation analysis. European Journal of Operational Research. 1999;116(1):16-32.

[10] Ahn BS, Cho SS, Kim CY. The integrated methodology of rough set theory and artificial neural network for business failure prediction. Expert Systems with Applications. 2000; 18(2):65-74.

[11] Adnan Aziz M, Dar HA. Predicting corporate bankruptcy: where we stand? Corporate Governance: The International Journal of Business in Society. 2006; 6(1):18-33.

[12] Pendharkar PC. A threshold-varying artificial neural network approach for classification and its application to bankruptcy prediction problem. Computers \& Operations Research. 2005; 32(10):2561-82.

[13] McKendrick JH. Statistical analysis using SPSS. Key Methods in Geography. 2003:425-43.

[14] Ohlson JA. Financial ratios and the probabilistic prediction of bankruptcy. Journal of Accounting Research. 1980; 18(1):109-31.

[15] Beaver WH. Financial ratios as predictors of failure. Journal of Accounting Research.1966:71-111.

[16] Springate GL. Predicting the possibility of failure in a Canadian firm: A discriminant analysis (Doctoral dissertation, Simon Fraser University). 1978.

[17] Salchenberger LM, Cinar E, Lash NA. Neural networks: A new tool for predicting thrift failures*. Decision Sciences. 1992;23(4):899-916.

[18] Tam KY, Kiang MY. Managerial applications of neural networks: the case of bank failure predictions. Management Science. 1992;38(7):926-47.

[19] Fulmer JG, Moon JE, Gavin TA, Erwin JM. A bankruptcy classification model for small firms. Journal of Commercial Bank Lending. 1984; 14: 2537.

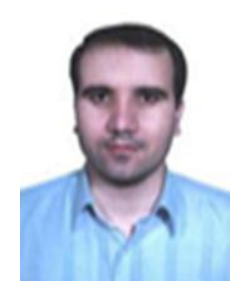

DR. Ali Mansouri, is an operation research Assistant Professor at Zanjan university, Ph.D from Tarbiyat Modares University with first rank inthe operating systemm. 12 years teaching experience in a university, research interests in OR, DEA, finance, quality management system, neural network prediction and decision making models. He is publishing more than 20 papers in national and international journals.

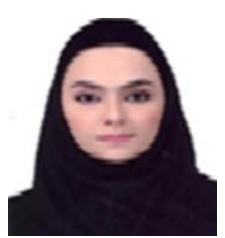

Arezoo Nazari, is a Master of accounting from the Saveh Azad University. Her research interest areas are finance and accounting. Currently, she is teaching in the Sofi Razi university.

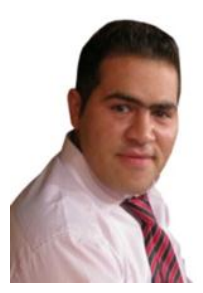

Morteza Ramazani, He is a member of the Young Researchers and Elite Club, Chief Financial Officeroft Zanjan Poultry Slaughterhouse company and research in the areas of Accounting Information System, Management Accounting and Information Technology. He has 45 papers in national and international journals. $\mathrm{He}$ is one of the top authors on Social Science Research Network (SSRN). He is the fullest appreciated to his father, mother and wife, Mr. Qudrat Ramazani and Mrs. Soghra Nagilou and Mrs. Narges Nikkhahbahrami for all the hard work they have suffered throughout his life and wish them health.

Email: mortezaramazani@ymail.com 